\title{
Effect of Pollution on Mechanical Properties of Foundations in Towers of Electrical Transmission
}

\author{
González Rolón Bárbara*, Fuentes Castañeda Pilar \\ Mechanical Engineering Department, Faculty of Engineering University of Guanajuato, Salamanca, Mexico \\ Email address: \\ barbara@ugto.mx(G. R. Bárbara) \\ *Corresponding author
}

To cite this article:

González Rolón Bárbara, Fuentes Castañeda Pilar. Effect of Pollution on Mechanical Properties of Foundations in Towers of Electrical Transmission. American Journal of Mechanical and Materials Engineering. Vol. 2, No. 1, 2018, pp. 1-7. doi: 10.11648/j.ajmme.20180201.11

Received: February 27, 2018; Accepted: March 21, 2018; Published: April 18, 2018

\begin{abstract}
The effect of meteorological variables such as relative humidity, maximum temperature, and predominant wind orientation, as well as oxidant species on the variation of mechanical resistance to compression of the cylinders extracted from two electric transmission towers was investigated. The obtained results are compared with the mechanical strength to compression achieved in concrete cylinders prepared in the laboratory and submerged in solutions of nitric acid and sulfuric acid in concentrations taken from the statistical data of nitrous oxide and sulfurous present in the environment where have installed the towers under study. The results show a decrease in the mechanical strength of the exposed cores in the predominant direction of the wind and of the cylinders submerged in the solution with acids, concluding that both conditions favor the degradation of concrete properties.
\end{abstract}

Keywords: Concrete Cylinders, Mechanical Strength, Meteorological Variables, Pollution, Transmission Towers

\section{Introduction}

One of the most significant effects of global climate change is the increase in the rate of deterioration of reinforced concrete structures due to the corrosion induced by carbonation Reference [1] shows with penetration, by diffusion from the external environment, the carbon dioxide reacts with the calcium hydroxide present in the hydrated concrete, forming the calcium carbonate. This reaction known as carbonation decreases the alkalinity of the concrete by breaking the passive film around the reinforcing rod that prevents corrosion [2].

Reference [3] conducted a study on structures of old and new bridges in three different locations in South Africa; considering the climatic conditions as relative humidity, temperature, and precipitation. Exposed elements such as parapets, pillars, walls, edges, to mention a few, were of particular interest because corrosion occurs in them because of high moisture content. The optimum range of relative humidity $(\mathrm{RH})$ for carbonation is between $50 \%$ and $75 \%$.

The study by [1] shows that the amount of rain would affect the surfaces of the concrete with erosion, as well as the diffusion of contaminants to the interior of the surface. The study is carried out in the cities of Toronto and Vancouver, considered as the most significant urban centers in Canada, developing a model to predict the effects of climate change on the carbonation of concrete. They conclude that the carbonation depth is higher in Toronto due to the low relative humidity, considered of $73.2 \%$. Reference [4] investigated different aspects to determine the speed of corrosion and deterioration of some metallic materials, which constitute the distribution networks of electric energy, in various environments of the Brazilian coast. They implemented meteorological stations to help evaluate the aggressiveness of atmospheric pollutants, considering corrosive environments due to salinity and industrial pollutants and less aggressive in regions remote from the source of those pollutants.

Reference [5] mention three kinds of geographic environments used within the transmission industry: nonpolluted (rural), polluted (industrial) and coast. Due to the different corrosive characteristics, each environment will have different effects on the life of the lines and towers over the service life. The study of variables that influence the process of atmospheric corrosion is of fundamental importance since many materials present in daily life are susceptible to degradation [4].

According to the above, in this investigation the analysis 
of concrete deterioration is performed on the compressive strength values obtained from the foundations of two electrical transmission towers, evaluating different environmental variables and contaminant species present in the study area.

\section{Materials and Methods}

Of two electrical transmission towers, eight cylindrical concrete cores were obtained from the foundation. These are known as cores and are extracted by drilling the concrete mass with a thin-walled cylindrical drill [6], the diameter of these are approximately $7.5 \mathrm{~cm}$ by $15 \mathrm{~cm}$ in length, images of two cores are presented in Figure 1.

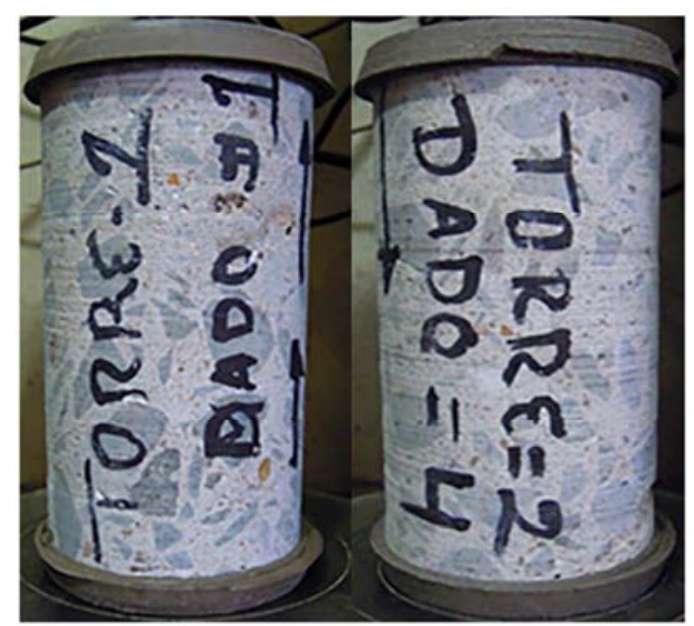

Figure 1. Cores extracted from two electric transmission towers.

This type of sample is obtained when there is doubt about the quality of the concrete in place, either because of a low value of resistance achieved during the construction or by signs of structural damage. However, one more use is to provide information about resistance in older structures [42]. The study samples were identified as $\mathrm{T} 1 \mathrm{C} 1, \mathrm{~T} 2 \mathrm{C} 1$, etc., where $\mathrm{T} 1$ and $\mathrm{T} 2$ represent the tower number from which they were extracted, $\mathrm{C}$ is the core, and the final number corresponds to the foundation of each leg of the reference tower, four for each one, Figure 2.

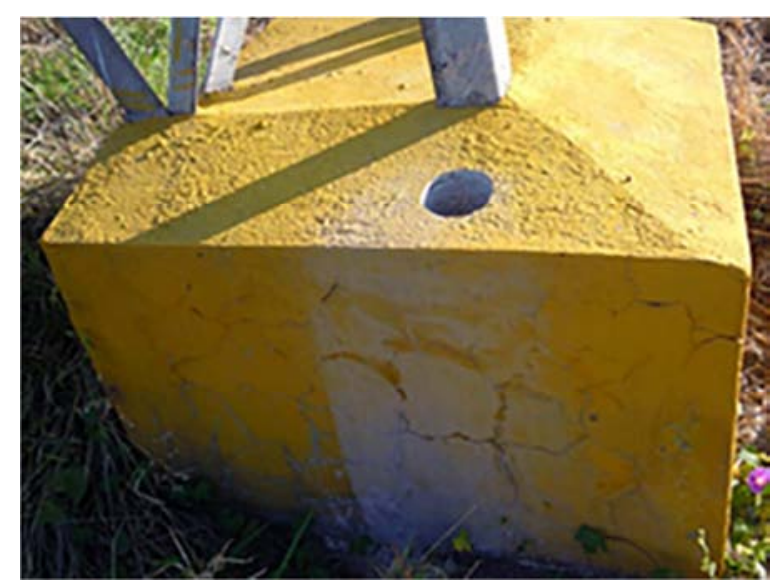

(a)

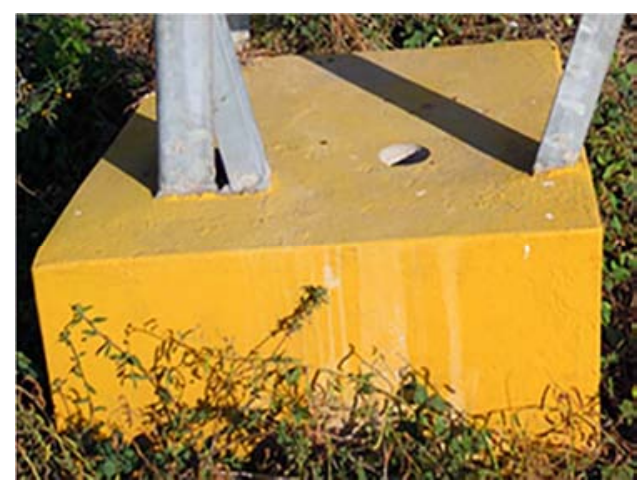

(b)

Figure 2. Core extraction foundations: (a) T1C1, (b) T2C3.

The samples $\mathrm{T} 1 \mathrm{C} 1$ and $\mathrm{T} 2 \mathrm{C} 4$ had defects, which can be seen in Figure 3.

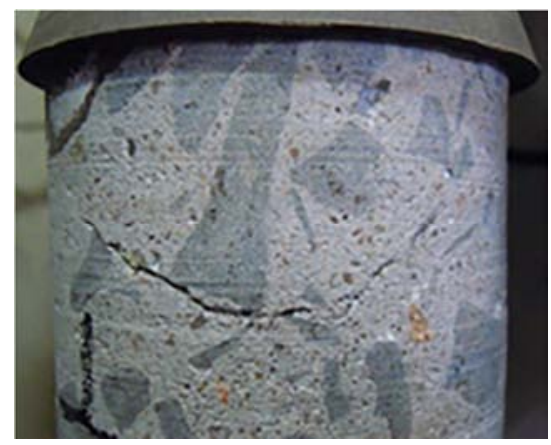

(a)

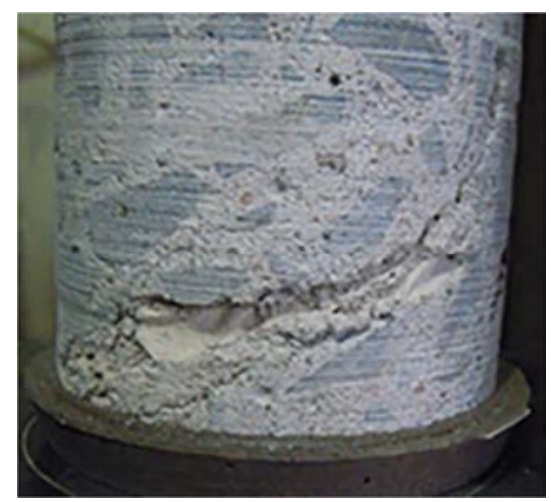

(b)

Figure 3. Core defects: a) T1C1 and (b) T2C4.

The standard further states that if the compression tests were performed using an ELVEC brand machine with a capacity of 120 tons. The standard also says that if the length/diameter ratio of the samples is 1.75 or less, the value obtained is multiplying by the correction factor given in Table 1 should be corrected, interpolation is allowed [8].

Table 1. Correction factors.

\begin{tabular}{lllll}
\hline $\mathrm{L} / \mathrm{D}$ & 1.75 & 1.5 & 1.25 & 1.00 \\
\hline Factor & 0.98 & 0.96 & 0.93 & 0.87 \\
\hline
\end{tabular}

Corrosion due to carbonation usually occurs in reinforced concrete structures, especially in urban areas where there is 
usually a high concentration of carbon dioxide in the air emitted by vehicles or industrial factories. The carbonation of concrete is defined as the chemical reaction between the carbon dioxide present in the atmosphere and the products of cement hydration [9].

A test to determine the depth of carbonation in the concrete is the use of a chemical indicator prepared by phenolphthalein in ethyl alcohol. This solution is colorless at $\mathrm{pH}$ values below 9 , for values higher than nine it turns purple [10], [1].

In addition to the cores, 7 cylindrical samples measuring $15 \mathrm{~cm}$ in diameter by $30 \mathrm{~cm}$ in height were prepared with a design strength of $200 \mathrm{~kg} / \mathrm{cm}^{2}$, following the specifications for foundations of electrical transmission towers dictated by the regulatory body in Mexico, Commission Federal Electricity CFE. The samples were demolding 24 hours after the casting and 28 days were maintained in a curing room at $100 \%$ relative humidity with the controlled temperature between $20^{\circ} \mathrm{C}$ and $25^{\circ} \mathrm{C}$, these conditions are considered as conventional curing, Figure 4.

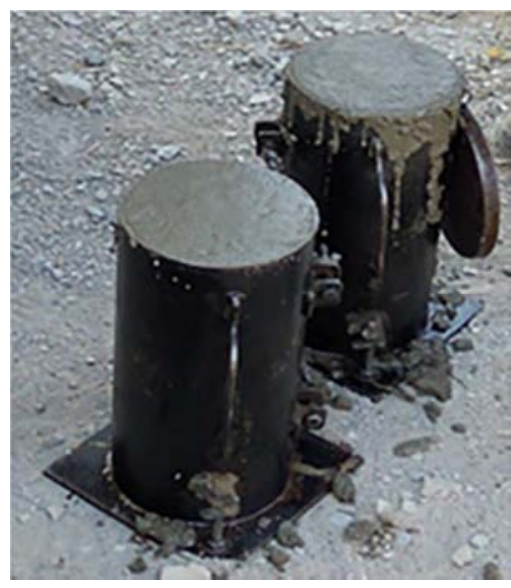

(a)

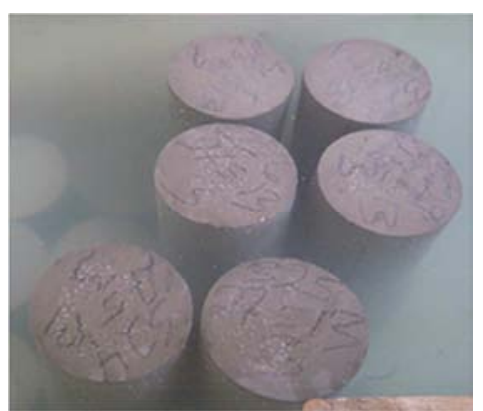

(b)

Figure 4. Molded cylindrical samples.

These samples were identified as CS1-CS7 where C is a cylinder, Specimen $\mathrm{S}$ and number is for each sample, for test [8]ASTM C-39 was applied using an FIIC brand machine with a capacity of 120 tons. The compression tests of samples CS1, $\mathrm{CS} 2, \mathrm{CS} 3$, and CS4 were performed at 3, 7 and 28 days of regular curing. After this curing time, the CS5, CS6, and CS7 samples were kept moist, testing the CS5 sample for seven days after that, while the CS6 and CS7 samples were subjected to a solution consisting of $0.10 \mathrm{ml}$ of Nitric acid and $0.02 \mathrm{ml}$ of Sulfuric acid for 7 and 28 days, respectively. The concentrations and type of acid were determined according to the data obtained from the pollutants present in the environment surrounding the towers under study.

\section{Results and Discussion}

The results of the compressive strength of the cores are summarized in Table 2. To obtain the mechanical compressive strength was divided the maximum load supported by the sample during the test, between its crosssectional area, the length/diameter ratio for the sample T1C2 is 1.33 , less than 1.75 so it was necessary to make use of correction factors.

Table 2. Resistance to compression in cores.

\begin{tabular}{|c|c|c|c|c|c|c|}
\hline Sample & Diameter (cm) & Height (cm) & Mass (kg) & Load (kg) & Resistance $\left(\mathrm{kg} / \mathrm{cm}^{2}\right)$ & Resistance (MPa) \\
\hline $\mathrm{T} 1 \mathrm{C} 1$ & 7.5 & 15 & 1.485 & 10500 & 237.6 & 23.3 \\
\hline $\mathrm{T} 1 \mathrm{C} 2$ & 7.5 & 10 & 0.974 & 15500 & 329.6 & 32.3 \\
\hline $\mathrm{T} 1 \mathrm{C} 3$ & 7.5 & 14.5 & 1.457 & 15080 & 341.3 & 33.4 \\
\hline $\mathrm{T} 1 \mathrm{C} 4$ & 7.5 & 15 & 1.496 & 18620 & 421.5 & 41.3 \\
\hline $\mathrm{T} 2 \mathrm{C} 1$ & 7.5 & 15 & 1.517 & 16110 & 364.6 & 35.7 \\
\hline $\mathrm{T} 2 \mathrm{C} 2$ & 7.5 & 14.8 & 1.502 & 18580 & 420.6 & 41.2 \\
\hline $\mathrm{T} 2 \mathrm{C} 3$ & 7.5 & 15 & 1.489 & 11100 & 251.3 & 24.6 \\
\hline
\end{tabular}

The tendency of the concrete to increase its compressive strength with the passage of time, in structures in service, can be seen in the values obtained for the hearts $\mathrm{T} 1 \mathrm{C} 4$ and $\mathrm{T} 2 \mathrm{C} 2$. When comparing the results of the eight cores with the design strength of $200 \mathrm{~kg} / \mathrm{cm} 2$ and according to applied standard, the obtained values of resistance are satisfactory since none of them is $35 \mathrm{~kg} / \mathrm{cm} 2$ smaller than the design resistance. It can be explained because, in the presence of water, it reacts with calcium hydroxide to generate calcium oxide and hydrated silicon the compound that is the key contributor to concrete strength. Supplemental complex formation during cement hydration due to the pozzolanic reaction can improve concrete properties such as strength and durability. The cement-pozzolan-water mixture is a complex system, consisting of many physicochemical processes that are influenced by temperature, mixing proportion, pozzolan reactivity, pozzolan particle size and other factors. The water in pores can also fracture the concrete by alternate freezing and thawing, thereby enhancing further water penetration. So the sample T2C4 presents a low resistance value compared to the other cores, in this sample, the fracture initiation was present before the 
test Figure 5. When the test was applied, the fracture followed the path of the defect. It is important to mention that cores are subject to variable ambient conditions in service and varying conditions after extraction. Cores are tested in the dry or wet condition, rarely in the saturated condition as the cylinders cured in the laboratory [12].

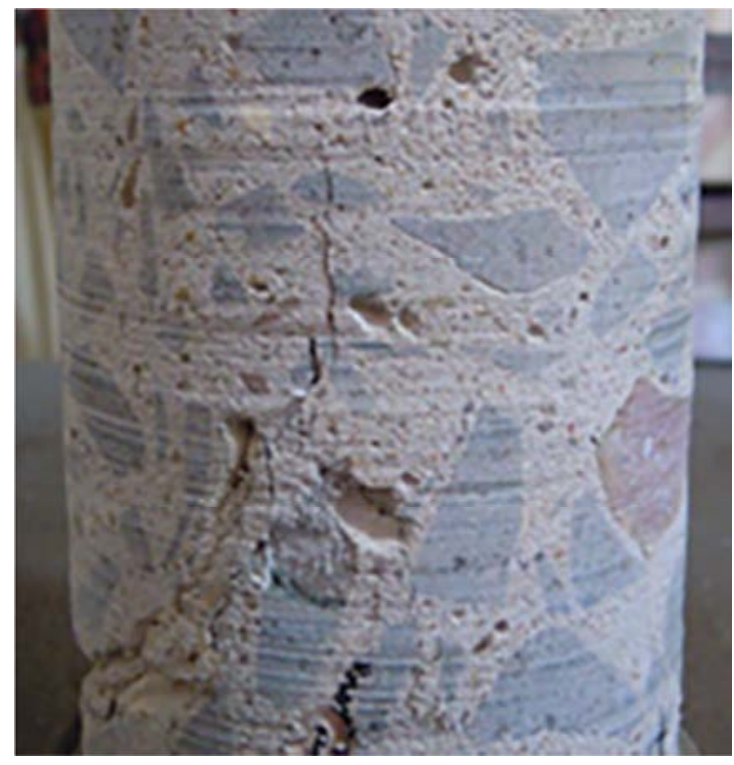

Figure 5. The drift of T2C4 heart fracture.

The diagram of Figure 6 shows the arrangement of the foundations of the transmission towers, including the nomenclature of the extracted core and its corresponding value of the results of mechanical resistance to compression obtained from the tests in $\mathrm{kg} / \mathrm{cm}^{2}$.

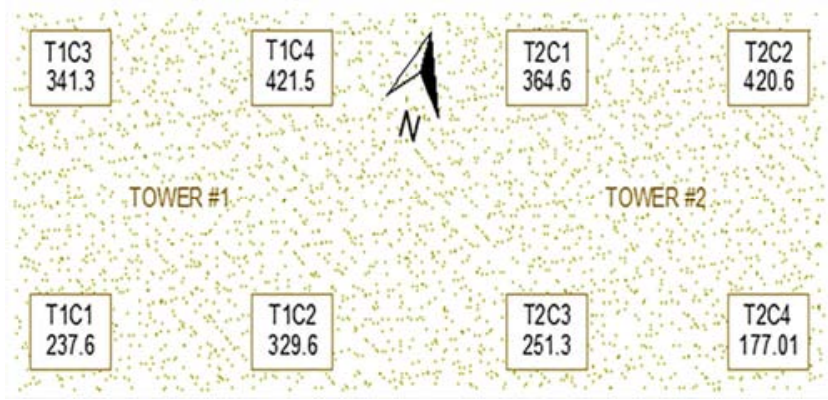

Figure 6. Distribution of foundations in transmission towers.

According to the research carried out by [13], it is necessary to make a study of meteorological and environmental aspects that affect the area where the concrete structures are since the pollutants have variable proportions that depend on the proximity of emission sources, local conditions and the action of the wind, which leads to the degradation of concrete structures in aggressive environments. Statistical information on parameters such as relative humidity $(\mathrm{RH})$, wind speed, maximum temperature, minimum temperature and dominant wind direction was obtained for one year three months before the extraction of hearts [14]. Table 3 shows the average values of these parameters.
Table 3. Prevailing meteorological variables.

\begin{tabular}{llllll}
\hline Variable & $\begin{array}{l}\text { T max } \\
\left({ }^{\circ} \mathbf{C}\right)\end{array}$ & $\begin{array}{l}\text { T min } \\
\left({ }^{\circ} \mathbf{C}\right)\end{array}$ & $\begin{array}{l}\text { RH } \\
(\mathbf{\%})\end{array}$ & $\begin{array}{l}\text { Avg Speed } \\
(\mathbf{k m} / \mathbf{h})\end{array}$ & $\begin{array}{l}\text { Dom. Dir. } \\
\left({ }^{\circ}\right)\end{array}$ \\
\hline & 27.6 & 12.1 & 62.6 & 5.57 & NO-SO \\
\hline
\end{tabular}

Table 4 shows the average values of some contaminants to city Irapuato Guanajuato, the analysis of this data reveal that the dominant orientation of the wind comes from the west and the days in which it occurred correspond to the rainy season in the region. The city Irapuato Guanajuato, and cultivated land are in the dominant direction of the wind where the transmission towers under study are located. The city has an industrial environment, the contaminants present include nitrogen oxide and sulfur dioxide, which when reacted with water producing nitric and sulfuric acid.

Table 4. Contaminants present in the study area [15].

\begin{tabular}{lllll}
\hline Year & $\mathbf{S O}_{\mathbf{2}}(\mathbf{p p b})$ & $\mathbf{N O}_{\mathbf{2}}(\mathbf{p p b})$ & $\mathbf{P M}_{\mathbf{1 0}}$ & $\mathbf{C O}(\mathbf{p p m})$ \\
\hline 2008 & 12 & 116 & 43.6 & - \\
2009 & 14 & 106 & 46.8 & - \\
2010 & 11 & 64 & 42.1 & 4.5 \\
2011 & 16 & 116 & 54.0 & -- \\
\hline
\end{tabular}

The Portland is the first cement of the concrete is initially a mixture of calcium aluminate and calcium silicate both undergo hydration to generate the bond. The relative humidity for the occurrence of carbonation is between $50 \%$ and $75 \%$, the value of $62.6 \%$ of $\mathrm{RH}$ obtained in the study area, is within the ideal conditions for the occurrence of carbonation in the foundations of the towers of transmission. It is known that if the hydration reactions are not complete, then some of the not hydrated constituents may carbonate [3]. Consequently, we expect that a particular competition between hydration and carbonation reactions may take place, the carbon dioxide dissolved in water forming carbonic acid, and reduces $\mathrm{pH}$ by dissociation to protons, and the bicarbonate ion:

$$
\begin{gathered}
\mathrm{CO}_{2}+\mathrm{H}_{2} \mathrm{O} \rightarrow \mathrm{H}_{2} \mathrm{CO}_{3} \rightarrow \mathrm{H}^{+}+\mathrm{HCO}_{3}^{-} \\
\mathrm{Ca}^{-2}+2 \mathrm{HCO}_{3}{ }^{-} \rightarrow \mathrm{Ca}\left(\mathrm{HCO}_{3}\right)_{2} \rightarrow \mathrm{CaCO}_{3}+\mathrm{CO}_{2}+\mathrm{H}_{2} \mathrm{O}
\end{gathered}
$$

When the calcium carbonate precipitates, produce corrosion. The corrosion is measured by saturation index (SI) [16], which is defined by:

$$
\mathrm{SI}=\mathrm{pH}-\mathrm{pHs}
$$

Where $\mathrm{pH}$ is experimentally measured, and $\mathrm{pHs}$ is the $\mathrm{pH}$ value at which the water is in equilibrium with solid calcium carbonate. A positive SI indicates sufficient alkalinity and calcium carbonate will precipitate. The solution of phenolphthalein poured in the extracted cores, present a very marked purple coloration, as it shows Figure 7, which indicates carbonation present in the cores.

Calcium hydroxide, leaches out of uncured Portland cement upon addition of water, forming an alkaline solution that produces an initially resistant passive film on the steel surfaces. During curing, water first reacts with the cement compounds, and the excess then evaporates out of the 
hardened structure concentrating the Calcium hydroxide solution in pores and voids and further increasing the corrosion resistance of the reinforcing steel. No damage occurs in dry concrete due to the absence of essential water. Nor is there much loss in continuous water saturated concrete because oxygen has less access through the liquid phase than through air in the concrete pores dissolved chlorides are essential in corrosion damage concrete [17].

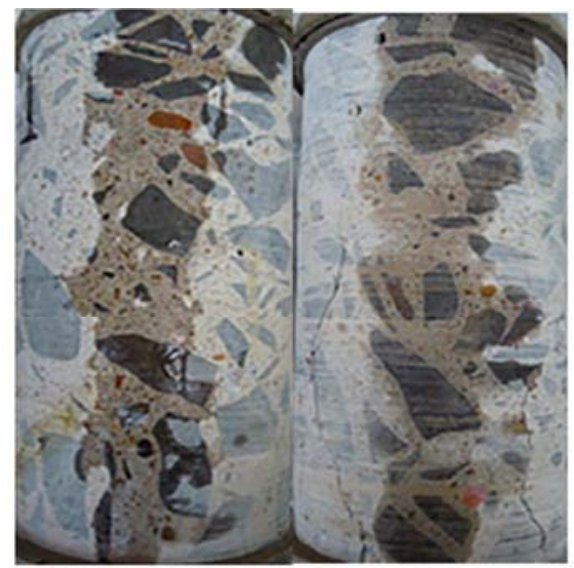

(a)

(b)

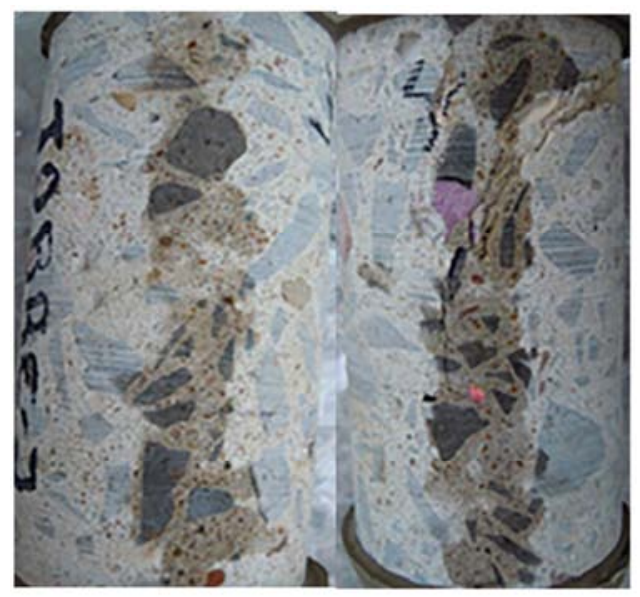

(c)

(d)

Figure 7. Test of phenolphthalein in tower number two hearts.

The concrete is gravel with a mixture of sand to fill the pores space. That is still in the sand is full of a paste of cement and water. The cement is hydrated does not dry to form a bond inside the concrete. The experience marks the advantage of allowing a small percentage of air bubbles, this air improves the handling of the concrete during its placement but more important is that these increase the resistance of the concrete to the deterioration that results from freezing and thawing. If the aggregate is stronger than cement, it is the property of the pulp that governs the properties of the concrete. Consequently, concrete having a low ratio of water to cement is more resistant than concretes with higher ratios. With low ratio, there is more hydrated cement and less excess water in the spaces.

\section{Cements}

$$
\begin{aligned}
& \mathrm{Ca}_{3} \mathrm{Al}_{2} \mathrm{O}_{6}+6 \mathrm{H}_{2} \mathrm{O} \rightarrow \mathrm{Ca}_{3} \mathrm{Al}_{12}(\mathrm{OH})_{12} \\
& \mathrm{Ca}_{2} \mathrm{SiO}_{4}+x \mathrm{H}_{2} \mathrm{O} \rightarrow \mathrm{Ca}_{2} \mathrm{SiO}_{4} \cdot \mathrm{xH}_{2} \mathrm{O}
\end{aligned}
$$

In each reaction, the hydrated product is less soluble than the cement. Therefore in the presence of water, the above reactions are solution and precipitation. Other types of cement are classified as polymeric and reaction hydraulics. Hydraulics are those that have hydration reactions similar to Portland cement. Inorganic polymer cement is silicic acid. $\mathrm{xSi}(\mathrm{OH})_{4}$

$$
\begin{aligned}
\mathrm{Ca}_{2} \mathrm{SiO}_{4}+(5-\mathrm{y}+\mathrm{x}) \mathrm{H}_{2} \mathrm{O} & \rightarrow \mathrm{Ca}_{2}\left[\mathrm{SiO}_{2} \cdot \mathrm{OH}_{2}\right] 2 \cdot(\mathrm{CaO}) \mathrm{y}-1 . \mathrm{xH}_{2} \mathrm{O} \\
+ & (3-\mathrm{y}) \mathrm{Ca}(\mathrm{OH})_{2}
\end{aligned}
$$

Where $\mathrm{x}$ varies with the partial pressure of water and is approximately equal to 2.3

Sulfur oxides and nitrous oxides are nowadays reached in rural areas and with a higher incidence in urban areas. In areas of high environmental pollution and high rainfall, the $\mathrm{pH}$ reaches values close to 4 , which is known as acid rain, which affects concrete structures [18].

The results of the compressive strength of the molded samples are summarized in Table 5.

Table 5. Resistance to compression in molded samples.

\begin{tabular}{llllll}
\hline Sample & $\begin{array}{l}\text { Mass } \\
(\mathbf{k g})\end{array}$ & $\begin{array}{l}\text { Load } \\
(\mathbf{k g})\end{array}$ & $\begin{array}{l}\text { Resistance } \\
\left(\mathbf{k g} / \mathbf{c m}^{2}\right)\end{array}$ & $\begin{array}{l}\text { Resistanc } \\
\mathbf{e}(\mathbf{M P a})\end{array}$ & $\begin{array}{l}\text { Age } \\
\text { (days) }\end{array}$ \\
\hline CS1 & 11.84 & 32000 & 181 & 17.8 & 3 \\
CS2 & 11.70 & 39000 & 220 & 21.6 & 7 \\
CS3 & 11.86 & 49000 & 277 & 27.2 & 28 \\
CS4 & 11.81 & 49400 & 279 & 27.4 & 28 \\
CS5 & 11.72 & 51000 & 288.6 & 28.3 & 35 \\
CS6 & 11.72 & 58000 & 328.2 & 32.2 & 86 \\
CS7 & 11.86 & 60000 & 339.6 & 33.3 & 107 \\
\hline
\end{tabular}

The results of the investigation show the increase of the compressive strength under normal curing conditions in samples CS1, CS2, CS3, CS4, and CS5. However, the resistance of CS6 and CS7 samples is affected when the acids solutions are applied. As the hydration continues, the concrete becomes harder and stronger, which occurs over the first month, but if there are adequate humidity and temperature, this continues more slowly for a more extended period, which exceeds thirty years in which a continuous increase in resistance has been reported. The increase in strength with age continues as long as the no hydrated cement is still present, the concrete remains wet, or the relative humidity of the air is above about $80 \%$, and the temperature of the concrete remains favorable [12]. In Figure 8 the exponential adjustment of the tendency to increase the compressive strength is presented in blue, considering the results of samples CS1, CS2, CS3, and CS4; while in red the values obtained from samples CS5, CS6 and CS7 are presented. The dots in purple indicate the compressive strength value for each core obtained. 


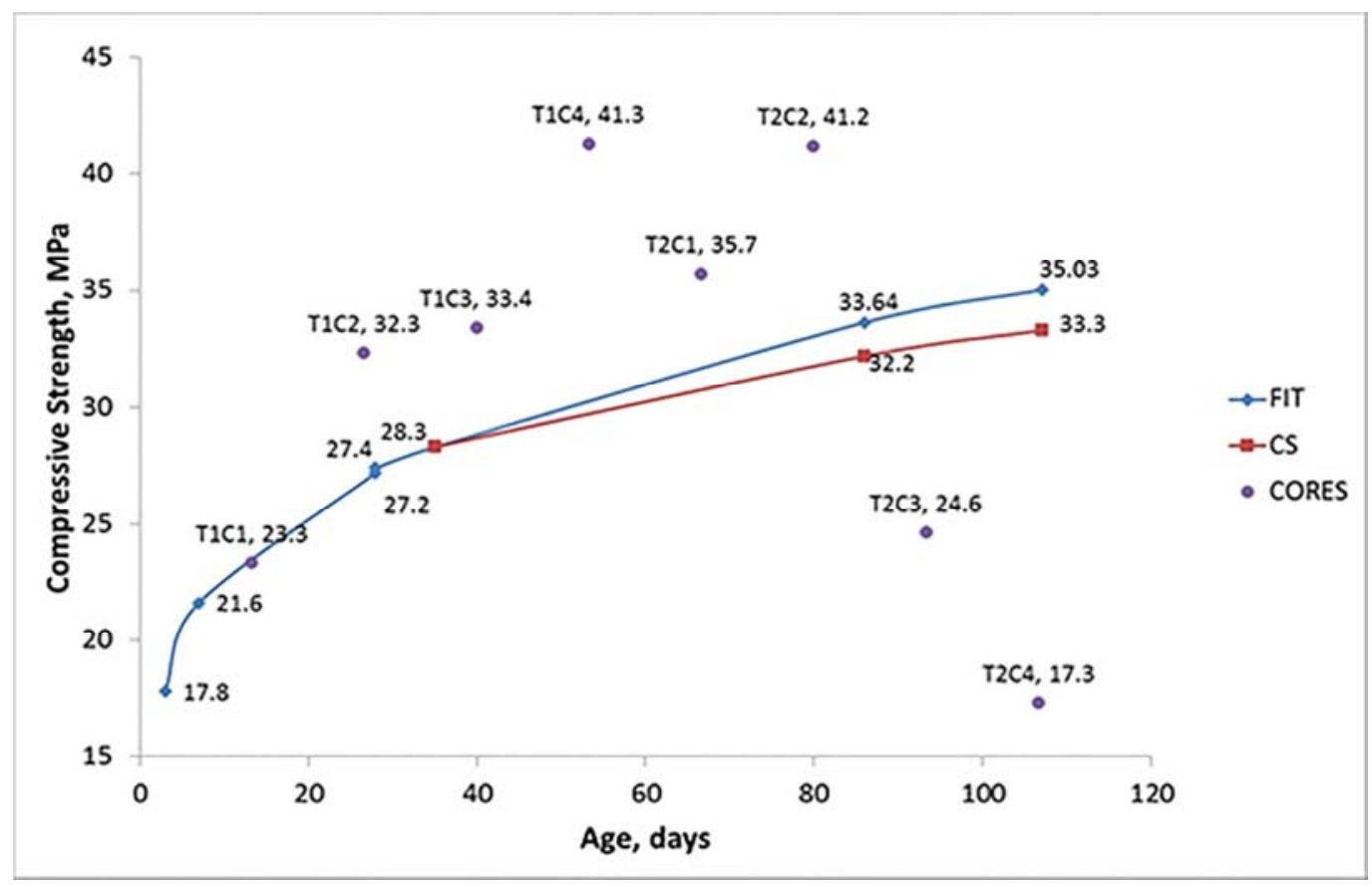

Figure 8. Compressive Strength - Time.

This graph shows that the value obtained in sample CS5, once moistened, falls in the trend line of resistance increase for normal curing conditions. However the values of the samples CS6 and CS7 are separated from this tendency, with which the presence of the acids causes the decrease of the value of mechanical resistance to compression. Also, the strength values of the cores in the prevailing wind direction are lower, concluding that these values are affected by the contamination conditions to which the transmission towers are exposed. It is important to mention that the actual age of the towers is ten years and that according to S. H. [12], higher values of resistance in the $\mathrm{T} 1 \mathrm{C} 1, \mathrm{~T} 1 \mathrm{C} 2, \mathrm{~T} 1 \mathrm{C} 3, \mathrm{~T} 2 \mathrm{C} 1$, $\mathrm{T} 2 \mathrm{C} 3$ and $\mathrm{T} 2 \mathrm{C} 4$ cores would be expected.

\section{Conclusion}

The evaluation of the compression results in the cores indicates different conditions of exposure of the concrete in the same area of study.

Pollution in the area surrounding the site of the transmission towers and the predominant wind direction in that direction are essential factors in the reduction of mechanical resistance to compression of cores.

The application of phenolphthalein reveals damage in concrete and allows to distinguish between carbonation and damage by the presence of polluting species in the environment.

The defect present in the core $\mathrm{T} 2 \mathrm{C} 4$ affected the value of mechanical compressive strength and the trend of the fracture in this sample.

The application of the nitric and sulfuric acids in the molded samples, affect the value of the mechanical compressive strength of these specimens.

\section{References}

[1] S. Talukdar, N. Banthia, et al. "Carbonation in concrete infraestructura in the context of global climate change": Part2Canadian urban simulations. Cem. Concr. Compos. 34 (2012), pp. 931-935.

[2] P. F. Marques, C. Chastre, et al. "Carbonation service life modelling of RC structures for concrete with Portland and blended cements." Cem. Concr. Compos. 37 (2013), pp. 171184. DOI: S095894651730639X

[3] M. G. Alexander, J. R. Mackechnie, et al. "Carbonation of concrete bridge structures in three South African localities." Cem. Concr. Compos. 29 (2007), pp. 750-759. DOI: S0950061809003584

[4] F. J. L. Molina, M. C. A. Alonso, M. S. Moreno \& R. J. Centenero, "Corrosion protection of galvanized rebars in ternary binder concrete exposed to chloride penetration". Construction and Building Materials, 156, (2017) pp 468-475.

[5] G. Blackett, E. Savory, et al. "An evaluation of the environmental burdens of present and alternative materials used for electricity transmission." Build. Environ. 43(2008), pp. 1326-1338. DOI: S1877705812028081

[6] R. Aaron R. Grubbs, Adam C. Carroll, Anton K. Schindler, and. W. Robert Barnes. Evaluation of IN-Place Concrete Strength by Core Testing, Research Report No. 2 for AIDOT project 930-828-2, (2016) pp 12, 22.

[7] ASTM International 2007 FORTY FOURTH Edition STOCK Number; BLD607, C-42/C 42M-04: "Obtaining and testing drilled cores and sawed beams of concrete", Vol. 1 (2007) pag. x.

[8] American Society for Testing and Materials, C-39: "Compressive strength of cylindrical concrete specimens," ASTM, United States 2003. 
[9] S. A Ghahari, A. Mohammadi, A. A Ramezanianpour Performance Assessment of Natural Pozzolan Roller Compacted Concrete Pavements. Case studies in construction Materials Vol. 7, (2017) pp. 82-90.

[10] P. C. Borges, "Corrosión en estructuras de concreto armado" Teoría, inspección, diagnóstico, vida útil y reparaciones, IMCYC (2001) 46 pp. (in Spanish).

[11] M. Thomas. "The effect of supplementary cementing materials on alkali-silica reaction": A review. Cem. Concr. Res. 41 (2011), pp. 1224-1231.

[12] S. H. Kosmatka, B. Kerkhoff, et al. "Diseño y control de mezclas de concreto," Portland Cement Association (2004) 6 pp. (in Spanish).

[13] D. P. Cerqueira, K. F. Portella, et al. "Deterioration rates of metal and concrete structures in coastal environment of the South and Northeast Brazi"l: case studies in the Pontal do Sul, PR, and Costa do Sauípe, Bahia. Procedia Eng. 42 (2012), pp. 384-396.

[14] Fundación Guanajuato Produce A. C., Guanajuato-Exportar datos de la red de estaciones,

http://www.estaciones.fundacionguanajuato.mx/export/, (2016) (in Spanish).

[15] Instituto de Ecología del Estado de Guanajuato, "Programa de Gestión de Calidad para Mejorar la Calidad del Aire de Salamanca, Celaya e Irapuato 2013-2022”, SEMARNAT. (2013) 42, 44, 46, 48 pp. (in Spanish).

[16] H. H. Uhlig, "Corrosion and Corrosion Control," $3^{\text {rd }}$ ed., vol 1, Ed. R. W. Revie Wiley-Interscience, New York 1985. Pp. 229-231.

[17] D. A. Jones, "Principles and Prevention of Corrosion," Mc. Millan $2^{\text {nd }}$ ed. 1992. pp. 388-389.

[18] A. Valle, T. Pérez, et al. "El fenómeno de la corrosión en estructuras de concreto reforzado," SCT-Instituto Mexicano del Transporte. (2001) 40 pp. (in Spanish). DOI: S071850732009000300004

\section{Biography}

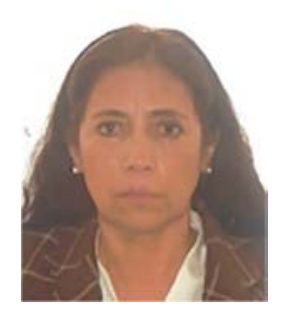

First A. Author Bárbara Gonzalez Rolón She graduated from the Ph.D. in Materials Science at the Universidad Nacional Autónoma de México in 1997. Since 1998 she was named Head of Materials Science group at the Universidad de Guanajuato, researching the field of dielectric materials. This research project is aimed to characterize the different elements involved in the degradation of ceramics. She works also looks to discover new dielectric materials with improved physicochemical properties. She is actively participating in research with several other groups from academia and industry.

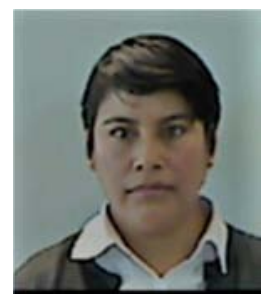

Second A. Author, Pilar Fuentes (Mexico) B. Sc. In Electromechanical Engineer, Technological Institute of Toluca, Mexico, 2003. M. Sc. In Mechanical Engineering, Specialty Mechanical Design, Engineering Division, Irapuato-Salamanca Campus, University of Guanajuato, 2014. Concrete and Cement Research. National Institute for Nuclear Research (2006-2011), Applied Sciences Manager, Department of Automation and Instrumentation. Academic Stay at Nagaoka University of Technology (Autum 2014), Research Report of Fly Ash. Ph. D. In Mechanical Engineering, Specialty Mechanical Design, Engineering Division, Irapuato-Salamanca Campus, University of Guanajuato, current. Concrete and Cement Research. 